04

\title{
Разряд между струйным жидким и металлическим электродами
}

\author{
() Ал.Ф. Гайсин, ${ }^{1}$ Н.Ф. Кашапов, ${ }^{2}$ А.И. Купутдинова, ${ }^{1}$ Р.А. Мухаметов ${ }^{1}$ \\ ${ }^{1}$ Казанский национальный исследовательский технический университет им. А.Н. Туполева - КАИ, \\ 420111 Казань, Россия \\ ${ }^{2}$ Казанский (Приволжский) фредеральный университет, \\ 420008 Казань, Россия \\ e-mail: almaz87@mail.ru
}

(Поступило в Редакцию 11 сентября 2017 г.)

Представлены результаты экспериментальных исследований низкотемпературной плазмы газового разряда, генерируемого в межэлектродном промежутке, где один электрод - струйный жидкий катод, второй - металлический анод. Представлены результаты исследований электрофизических и спектральных характеристик разряда, определен состав плазмы, даны оценки концентрации и температуры электронов, колебательной и вращательной температур тяжелой компоненты. Описаны формы и типы разряда, особенности газогидродинамических и тепловых процессов, протекающих на границе раздела сред.

DOI: $10.21883 / J T F .2018 .05 .45900 .2485$

\section{Введение}

Физика и применение электрического разряда в газах, генерируемого между твердыми электродами, достаточно подробно исследованы специалистами из различных научных школ [1,2]. Вместе с тем в последние два десятилетия к данным исследованиям добавилось новое направление в области формирования разряда с жидкими электролитическими электродами. Данный тип разряда генерируется в межэлектродном промежутке токами постоянного или переменного поля, где один или оба электрода являются жидкостью. В качестве жидкости применяются, как правило, растворы солей различной концентрации в технической или дистиллированной воде. Внимание специалистов направлено на исследование типов и форм генерируемого разряда, состава плазмы, распределения концентрации и энергии компонентов плазмы, электрофизических и спектральных характеристик разряда, газогидродинамических и тепловых процессов в зоне формирования разряда, построение математических моделей пробоя и горения разряда. Наряду с этим разряды с жидкими электролитическими электродами находят широкое применение в различных отраслях промышленного производства. В области машиностроения данный тип разряда успешно применяется для обработки внешней и внутренней поверхностей деталей и узлов машин из различных типов металлов и сплавов. В области здравоохранения разряд применяется для стерилизации изделий медицинского назначения, очистки воды и воздуха. Известны работы российских [3-10] и зарубежных [11-14] научных групп в данной области науки.

Несмотря на интерес фундаментальной науки и широкие возможности практического применения данного типа разряда, большинство исследований касается частного случая, когда металлический электрод погружен или находится над жидкостью. В то время как всевозрастаю- щее использование концентрированных потоков энергии и создание на этой основе технологических процессов требуют детального изучения физики и возможностей практического применения разряда, генерируемого между струйным жидким и металлическим электродами. С фундаментальной точки зрения необходимость таких исследований обусловлена тем, что многие положения физики газового разряда, генерируемого между твердыми электродами, недостаточны для описания процессов в разрядах, генерируемых в межэлектродном промежутке с добавлением струйного жидкого электрода. В данной системе генерации разряда возникают сложные нестационарные процессы, существует взаимозависимость между газогидродинамическими процессами в струе жидкости с особенностями формирования самого разряда, без учета которых построение объективных моделей нелинейных процессов в области низкотемпературной плазмы разрядов с жидкими электродами затруднено. В области прикладных исследований стоят актуальные задачи по локальной обработке поверхности изделий различного назначения с целью улучшения качества поверхностного слоя, где разряд со струйным жидким электродом может найти успешное применение.

Цель настоящей работы - экспериментальное исследование характеристик разряда, генерируемого между струйным жидким анодом и металлическим катодом при атмосферном давлении. Полученные результаты могут быть использованы при построении моделей нелинейных процессов в области низкотемпературной плазмы разрядов с жидкими электродами.

\section{Экспериментальная установка}

Исследование разряда между струйным жидким анодом и металлическим катодом осуществлялось на установке (рис. 1), где: 1 - раствор электролита, 2 электролитическая ячейка, 3 - пластина для подвода 
Таблица 1. Параметры зажигания разряда

\begin{tabular}{c|c|c|c|c|c|c}
\hline $\begin{array}{c}\text { Напряжение } \\
U, \mathrm{~V}\end{array}$ & $\begin{array}{c}\text { Ток } \\
I, \mathrm{~A}\end{array}$ & $\begin{array}{c}\text { Давление } \\
\text { внешней среды } \\
p, \text { Рa }\end{array}$ & $\begin{array}{c}\text { Скорость течения } \\
\text { струи жидкости } \\
v, \mathrm{~m} / \mathrm{s}\end{array}$ & $\begin{array}{c}\text { Диаметр } \\
\text { струи } \\
d, \mathrm{~mm}\end{array}$ & $\begin{array}{c}\text { Длина } \\
\text { струи } \\
l_{c}, \mathrm{~mm}\end{array}$ & $\begin{array}{c}\text { Удельная электро- } \\
\text { проводность электролита } \\
\sigma, \Omega^{-1} \mathrm{~cm}^{-1}\end{array}$ \\
\hline $100-1000$ & $0.4-5$ & $10^{5}$ & $0.1-0.4$ & $3-5$ & $10-30$ & $0.1-0.12$
\end{tabular}

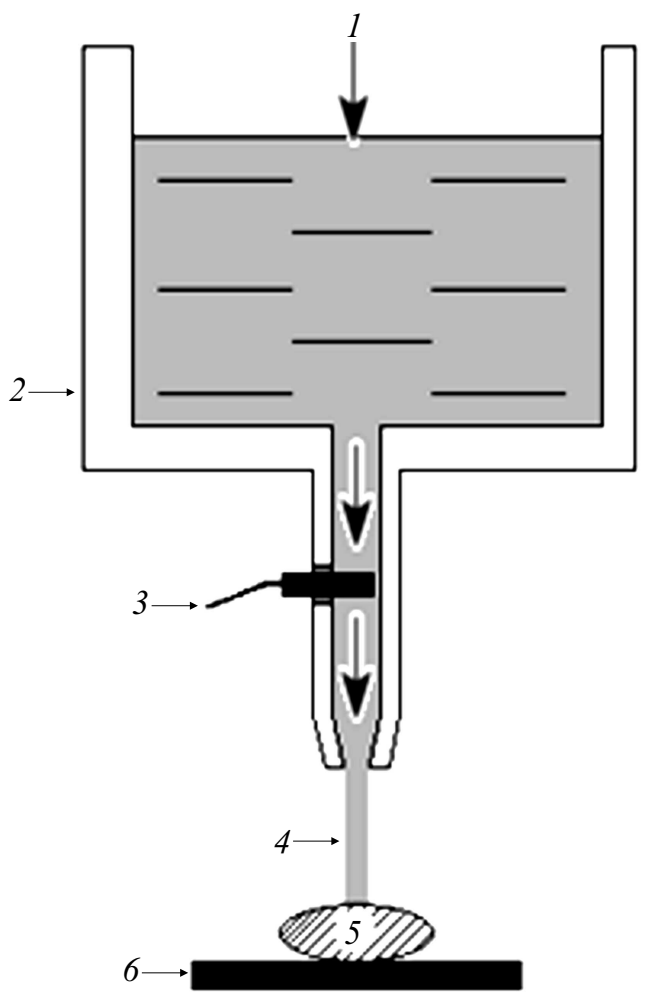

Рис. 1. Функциональная схема экспериментальной установки.

положительного потенциала в струю, 4 - струя, 5 зона формирования разряда, 6 - металлический катод. В качестве электролита использовался 7\% раствор $\mathrm{NaCl}$ в технической воде, а в качестве металлического катода - медная пластина марки М-1. В качестве источника питания использовался генератор постоянного тока, обеспечивающий подачу регулируемого постоянного напряжения до $4000 \mathrm{~V}$ при номинальном токе до $10 \mathrm{~A}$.

Параметры зажигания разряда представлены в табл. 1 .

Для решения поставленных задач применялись следующие методы исследования.

1. Исследования колебаний тока и напряжения газового разряда производились цифровым осциллографом марки „GDS-806S“.

2. Процесс горения газового разряда фиксировался с помощью цифровой фото-видеосъемки на аппаратуре марки ,SONY FDR-AX33“.

3. Для инфракрасной термографии поверхности электродов в зоне горения газового разряда применялся тепловизор марки „FLIRA6500SC“, для обработки получен- ных данных использовалось программное обеспечение ALTAIR v5.91.010.

4. Для визуализации пространственной структуры гидрогазодинамических процессов в зоне горения газового разряда применялся шлирен-метод (метод Теплера). Принцип работы и оптическая схема шлирен-системы представлены в работе [15].

5. Спектр излучения плазмы разряда определялся оптико-волоконным спектрометром марки „PLASUS

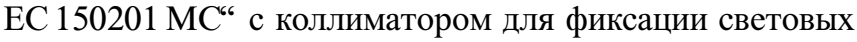
лучей в диапазоне длин волн от 195-1105 nm. Спектральное разрешение прибора $\delta \lambda=1 \mathrm{~nm}$. Исследуемое излучение собиралось с разряда, оценка состава и компонентов плазмы выполнена без привязки к конкретной области. Расшифровка спектра выполнялась идентификацией линии при помощи сопоставления исследуемого спектра с базой данных Национального института стандартов и технологий (NIST).

\section{Обсуждение результатов}

С подачей потенциала на электроды $U=200 \mathrm{~V}$ при внешнем давлении $p=10^{5} \mathrm{~Pa}$ в цепи возникает постоянный ток замыкания $I \approx 0.4 \mathrm{~A}$, при этом на поверхности медного катода наблюдается процесс интенсивного испарения электролита с образованием парогазовых пузырьков без формирования разряда. С увеличением $U$ до $500 \mathrm{~V}$ в системе возникает пробой с образованием микроразрядов вдоль струи анода и на границе взаимодействия струйного анода и медного катода (рис. 2). Формирование микроразрядов вдоль струи анода объясняется тем, что в области утончения струи на границе между формирующимися каплями электролита возникает разность потенциала с дальнейшим пробоем и разрывом струи. При $U=500 \mathrm{~V}$ микроразряды формируются в виде импульсов тока в диапазоне $I \approx 1.8-2.2 \mathrm{~A}$, с частотой генерации $v=30-100 \mathrm{~Hz}$, с соответствующими микроразряду участками падения напряжения до $400 \mathrm{~V}$, при этом ширина импульса составляет $\tau=2-10 \mathrm{~ms}$, что соответствует времени горения микроразряда в расширяющейся парогазовой оболочке. С увеличением $U$ до $700 \mathrm{~V}$ фиксируется увеличение $I \approx 2.2-4$ А с соответствующими разряду участками падения $U$ до $500 \mathrm{~V}$, при этом понижается $v=30-50 \mathrm{~Hz}$ (рис. 3), что связанно с увеличением энерговклада в микроразряд и возрастанием времени замыкания струйного жидкого катода на медный анод после пробоя. При повышении $U$ до $1000 \mathrm{~V}$ возрастает $I \approx 4-5$ А с соответствующими участками 
падения $U$ до $800 \mathrm{~V}$, частота и ширина импульса тока меняется незначительно. Вкладываемая в разряд мощность составляет $P \approx 0.72-4 \mathrm{~kW}$.

Из анализа спектра излучения разряда (рис. 4) следует, что в анализируемом участке плазмы присутствуют атомы и молекулы различного наименования (атомы цинка $\mathrm{ZnI}$, меди $\mathrm{CuI}$, кислорода OI, кальция $\mathrm{CaI}$, калия K I, железа Fe I, натрия Na I, хлора ClI, молекулы азота $\mathrm{N}_{2}$ и гидроксила $\mathrm{OH}$ ). Аппаратное уширение в рассматриваемом спектре проверено по линиям К I $(511.24 \mathrm{~nm})$. Минимальная ширина одиночных линий составила $\Delta \lambda_{g}=1 \mathrm{~nm}$, она и взята за оценку аппаратной ширины. Оценка концентрации электронов в плазме разряда определялась по нескольким водородным линиям серии Бальмера, однако регистрируемая интенсивность линии $H_{\beta}$ едва превышает шумовую составляющую спектра, в связи с этим для оценки концентрации электронов использовалась линия $H_{\alpha}(656.3 \mathrm{~nm})$. Ширина

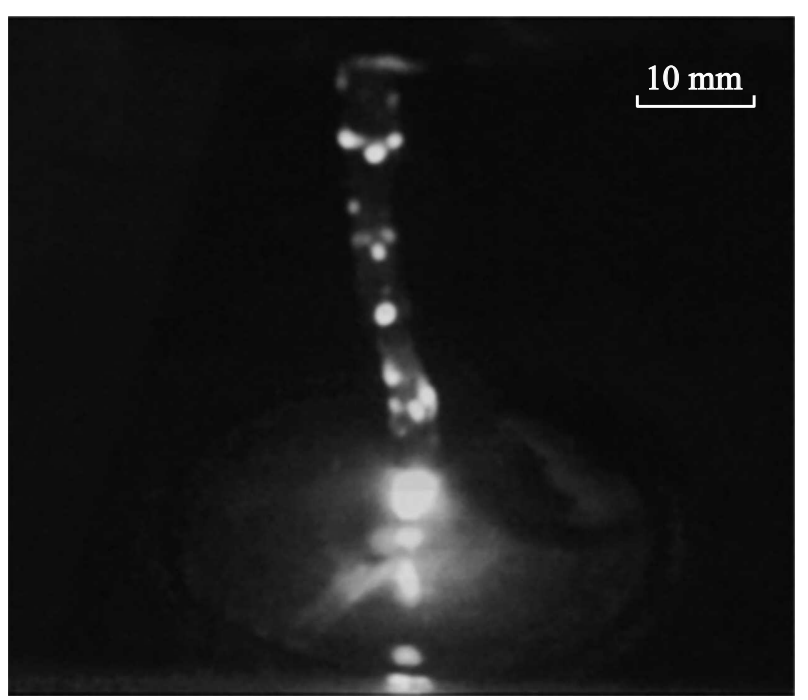

Рис. 2. Фотография разряда между струйным жидким анодом и медным катодом: $U=500 \mathrm{~V}, I \approx 1.8-2.2 \mathrm{~A}, l_{c}=30 \mathrm{~mm}$, $d_{c}=4 \mathrm{~mm}, p=10^{5} \mathrm{~Pa}$.

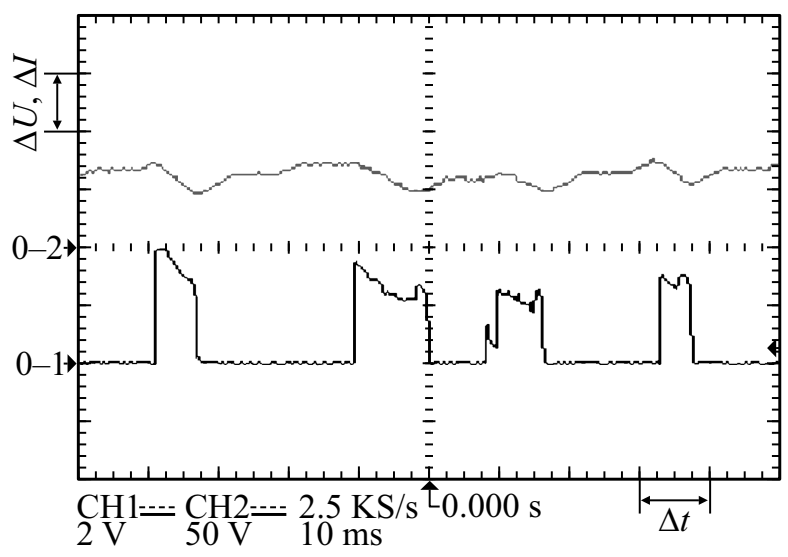

Рис. 3. Колебания тока и напряжения разряда: $\Delta U=500 \mathrm{~V}$, $\Delta I=2 \mathrm{~A}, \Delta t=10 \mathrm{~ms}$.

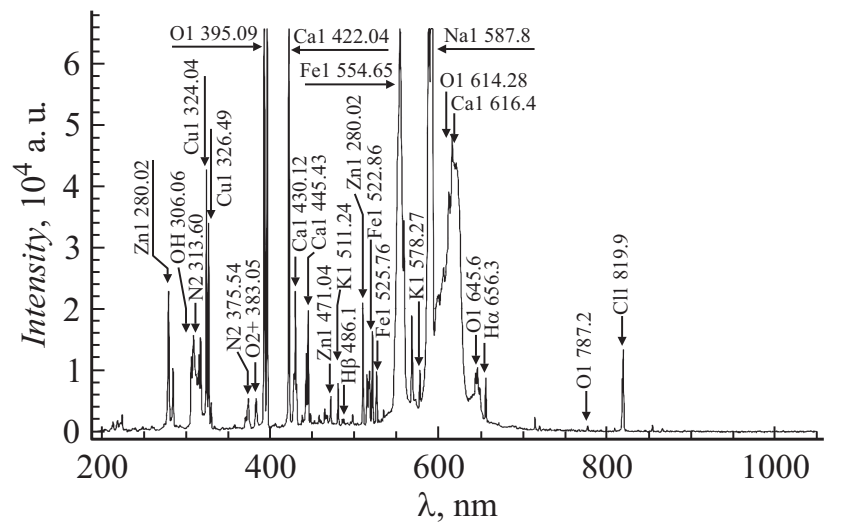

Рис. 4. Исследуемый спектр с отождествленными спектральными линиями.

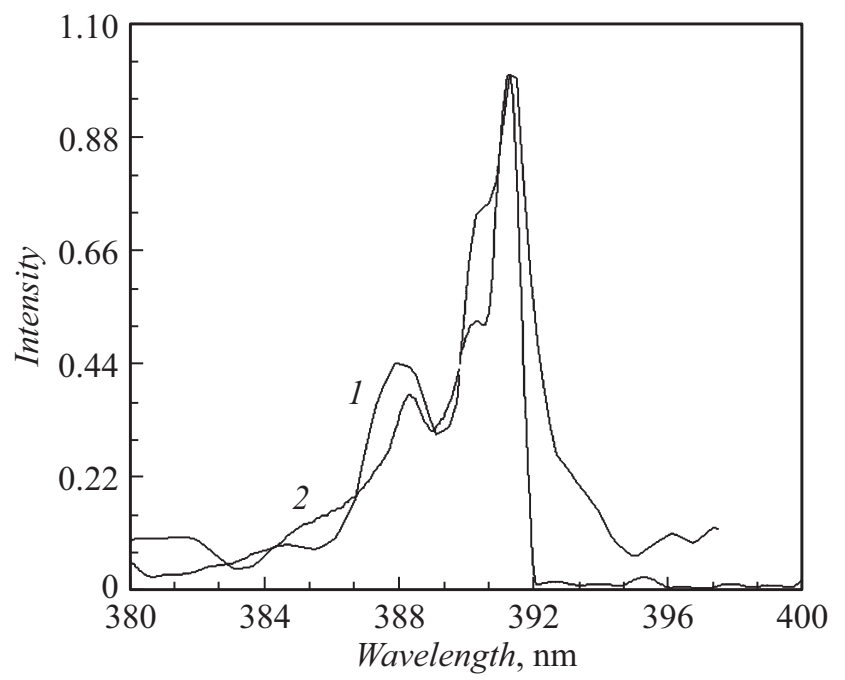

Рис. 5. Сравнение экспериментального спектра с моделью для молекулярной полосы $\mathrm{N}_{2}: 1$ - эксперимент, 2 - модель.

фойгтовского контура водородной линии $H_{\alpha}$, на ее полувысоте оказалась равна $\Delta \lambda_{f}=1.25 \mathrm{~nm}$. С учетом аппаратного уширения в предположении фойгтовского контура регистрируемой линии лоренцевская составляющая линии равна $\Delta \lambda_{L}=0.43 \mathrm{~nm}$. Согласно справочнику [16], величины $\Delta \lambda_{L}$, обусловленные линейным штарк-эффектом, соответствуют концентрациям электронов $n_{e}=3.77 \cdot 10^{16} \mathrm{~cm}^{-3}$. Для оценки температуры электронов предполагает наличие в плазме локального термодинамического равновесия $[17,18]$. Температура электронов определялась по атомным линиям одной кратности. Таким образом, температура электронов, рассчитанная по отношению интенсивности атомной линии FeI $520.86 \mathrm{~nm}$ к атомной линии Fe I $525.76 \mathrm{~nm}$, получилась равной $4600 \mathrm{~K}$.

Оценка колебательной и вращательной температур молекул проводилась сравнением экспериментального молекулярного спектра с расчетным по модели с варьируемыми колебательной $T_{v}$ и вращательной $T_{r}$ темпе- 


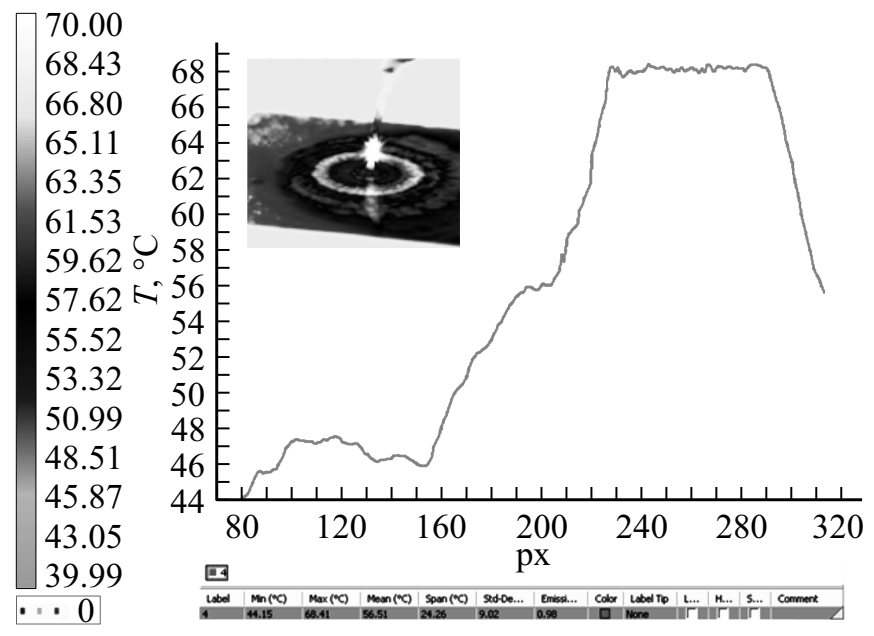

Рис. 6. Термограмма распределения температурных полей на поверхности струйного жидкого анода.

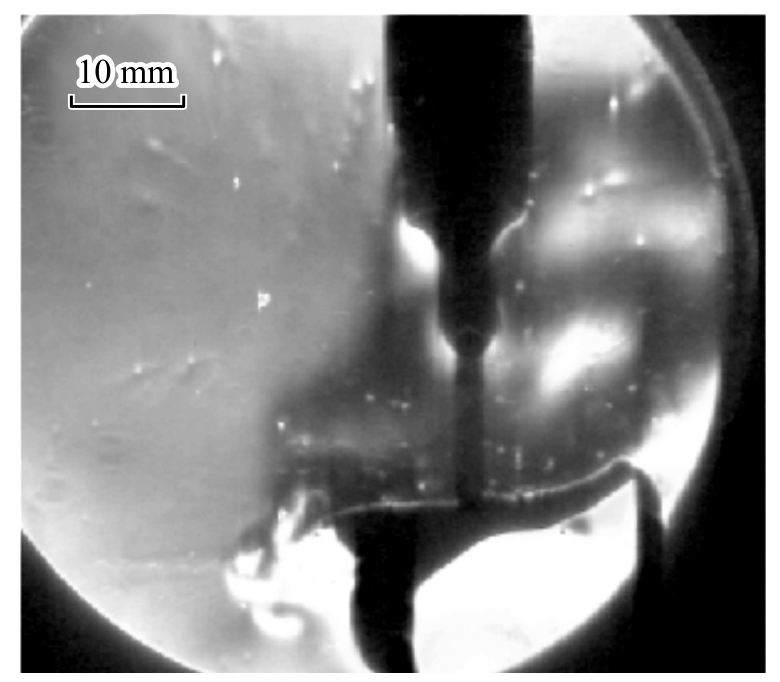

Рис. 7. Шлирен-изображение газогидродинамических процессов в зоне разряда между струйным жидким анодом и медным катодом.

ратурами в программном комплексе „Specair 2.2.0.0“. Оценка выполнена для полосы азота $\mathrm{N}_{2}$, так как данная серия линий проявилась наиболее четко. Сравнение экспериментального и модельного спектров для молекулярной полосы представлено на рис. 5. При этом наилучшее совпадение получилось при температуре $T_{v}=3700 \mathrm{~K}$ и $T_{r}=2150 \mathrm{~K}$ с учетом условий, что молекулярная полоса в своей „голове“ перекрывается со спектральной линией $\sim 306 \mathrm{~nm}$. Полученные данные по спектрам систематизированы в табл. 2.

Из анализа распределения температурных полей на поверхности струйного анода видно, что температура с места истечения струи до области формирования микроразряда возрастает от 44 до $68^{\circ} \mathrm{C}$ (рис. 6). Тогда как температура жидкости на поверхности медного катода циклично меняется от 48 до $59^{\circ} \mathrm{C}$, что связано
Таблица 2. Сравнение параметров плазмы разряда

\begin{tabular}{l|c}
\hline \multicolumn{1}{c|}{ Атомы } & $\begin{array}{c}\text { Zn I, Cu I, O I, Ca I, } \\
\text { K I, Fe I, Na I, Cl I }\end{array}$ \\
\hline Молекулы & $\mathrm{N}_{2+}, \mathrm{OH}$ \\
$n_{e}$, Концентрация электронов & $3.77 \cdot 10^{16}$ \\
$\left(\right.$ по $\left.H_{\alpha}\right), \mathrm{cm}^{-3}$ & \\
$T_{e}$, Температура электронов, K & 4600 \\
$T_{v}$, Колебательная температура, K & 3700 \\
$T_{r}$, Вращательная температура, K & 2150
\end{tabular}

c прохождением участков горячей жидкости с зоны горения разряда.

На рис. 7 представлены шлирен-изображения газогидродинамических процессов, протекающих на границе раздела сред в зоне горения разряда между струйным жидким анодом и медным катодом, где темные области соответствуют скачку уплотнения, а светлые разрежения. С подачей потенциала на электроды в цепи возникает постоянный ток замыкания и за счет джоулевого тепловыделения на границе между струйным жидким анодом и металлическим катодом протекает процесс испарения электролита с образованием на поверхности металлического электрода парогазовых пузырей. Если вкладываемая мощность недостаточна для ионизации межэлектродного промежутка, то в ней протекает процесс электролиза. Когда вкладываемая мощность достигает значения, достаточного для ионизации межэлектродного промежутка, то в парогазовых пузырях возникает пробой. Пробой сопровождается резким возрастанием тока и падением напряжения (рис. 3). В результате пробоя давление в парогазовых пузырях резко возрастает, что приводит к возникновению акустического хлопка с образованием ударных волн, которые распространяются в различных направлениях пространства. Ударные волны деформируют и отталкивают жидкий анод от металлического катода в случае формирования разряда на границе соприкасания электродов или разрывают струю в случае зажигания разряда в струе. В связи с этим межэлектродное расстояние возрастает, сопротивление в нем увеличивается, разряд гаснет, ток падает до нуля и тепловыделение вокруг металлического катода уменьшается. Далее парогазовая оболочка „схлопывается“, и жидкость замыкается с поверхностью металлического катода. Это приводит к резкому локальному тепловыделению с образованием парогазовых пузырей и повторным пробоем. Этот процесс периодически повторяется с $v \approx 30-100 \mathrm{~Hz}$.

\section{Заключение}

1. Установлено формирование импульсных микроразрядов в струе жидкости и на границе между струйным жидким анодом и медным катодом с вкладываемой 
мощностью $P \approx 0.72-4 \mathrm{~kW}$, частотой пульсации тока $v \approx 30-100 \mathrm{~Hz}$ и величиной тока импульса $I \approx 1.8-5 \mathrm{~A}$.

2. Концентрация электронов, полученная по уширению $H_{\alpha}$, равна $n_{e}=(3.77 \pm 0.40) \cdot 10^{16} \mathrm{~cm}^{-3}$.

3. Вращательная и колебательная температуры молекулы $\mathrm{N}_{2}$ оцениваются в $T_{r}=2150 \mathrm{~K}$ и $T_{v}=3700 \mathrm{~K}$ соответственно.

4. Электронная температура, рассчитанная по отношению интенсивности атомной линии FeI $520.86 \mathrm{~nm}$ к атомной линии FeI $525.76 \mathrm{~nm}$, получилась равной $4600 \mathrm{~K}$.

Работа проведена в рамках выполнения государственного контракта по постановлению № 220 Министерства образования и науки РФ, проект № 14.Z.50.31.0023 от 04.03.2014 г.

\section{Список литературы}

[1] Райзер Ю.П. Физика газового разряда. 3-е изд., перераб. и доп. Долгопрудный: Интеллект, 2009. 734 с.

[2] Фортов В.Е., Сон Э.Е., Бромберг Л., Гайсин Ф.М., Сон К.Э., О Джкон Хе, И Хе Ионг. Плазменные технологии (на корейском языке) МФТИ: KOFST, 2006. 135 с.

[3] Andre P., Barinov Y.A., Faure G., Shkol'nik S.M. // J. Phys. D: Appl. Phys. 2011. Vol. 44. N 37. P. 375202 (8 p.).

[4] Акишев Ю.С., Грушин М.Е., Каральник В.Б., Монич А.Е., Панькин М.В., Трушкин Н.И., Холоденко В.П., Чугунов В.А., Жиркова Н.А., Ирхина И.А., Кобзев Е.Н. // Физика плазмы. 2006. Т. 32. № 12. С. 1142.

[5] Гайсин А.Ф., Сон Э.Е., Петряков С.Ю. // Физика плазмы. 2017. T. 43. № 7. С. 625-633.

[6] Гайсин А.Ф., Сон Э.Е., Ефимов А.В., Гильмутдинов А.Х., Кашапов Н.Ф. // ТВТ. 2017. Т. 55. № 3. С. 472-475.

[7] Gaisin Al.F. // Inorganic Mater.: Appl. Res. 2017. Vol. 8. N 3. P. 392-395.

[8] Chebakova V.Ju., Gaisin A.F., Zheltukhin V.S. // IOP Publishing IOP Conf. Ser.: Mater. Sci. Engineer. 2016. Vol. 158. P. 012024.

[9] Максимов А.И., Титов В.А., Хлюстова А.В. // Химия высоких энергий. 2004. Т. 38. № 3. С. 227.

[10] Белялетдинов Т.Ш., Горячев С.В., Ефимов А.В., Исакаев Э.Х., Чиннов В.Ф. // Опт. и спектр. 2010. Т. 109. № 5. C. 721.

[11] Machala Z., Jedlovsky I., Chladekova L., Pongrac B., Giertl D., Janda M., Sikurova L., Polcic P. // Eur. Phys. J. D. 2009. Vol. 54. P. 195.

[12] Pongrác B., Machala Z. // IEEE Trans. Plasma Sci. 2011. Vol. 39. P. 2664.

[13] Kim H.H., Teramoto Y., Negishi N., Ogata A., Kim J.H., Pongrác B., Machala Z., Gañán-Calvo Alfonso M. // J. Aerosol. Sci. 2014. Vol. 76. P. 98.

[14] Bruggeman P., Leys Ch. // J. Phys. D: Appl. Phys. 2009. Vol. 42. P. 053001 (28 p).

[15] Нагулин К.Ю., Ибрагимов Р.И., Цивильский И.В., Гильмутдинов А.Х. // Опт. журн. 2012. Т. 79. № 4. С. 33-41.

[16] Касабов Г.А., Елисеев В.В. Спектроскопические таблицы для низкотемпературной плазмы. Спр. М.: Атомиздат, 1973. $160 \mathrm{c}$.
[17] Методы исследования плазмы / Пер. с англ. Под ред. В. Лохте-Хольтгревена. М.: Мир, 1971. 552 с.

[18] Биберман Л.М., Воробьев В.С., Якубов И.Т. Кинетика неравновесной изкотемпературной плазмы. М.: Наука, $1982.378 \mathrm{c.}$ 